\title{
Aquicultura: Impactos ambientais negativos e a mitigação com práticas agroecológicas
}

Ronald Assis Fonseca, Mauricio Novaes Souza, Pedro Pierro Mendonça, Hilton Moura Neto, Credigar Gonçalves Moreira, José Carlos V. da Paschoa, Lucinea Carolina Horsth, Aline Marchiori Crespo, Geisa Corrêa Louback

https://doi.org/10.4322/mp.978-65-991393-6-9.c2

\section{Resumo}

A aquicultura exerce um papel importante na economia mundial, na geração de emprego e na alimentação. Porém, não está restrita apenas aos aspectos sociais e econômicos: devem potencializar os aspectos ambientais. Devem ser considerados os fatores que envolvem a produção/criação de impactos e que podem contribuir com os desequilíbrios ambientais. Os impactos ambientais são alterações das propriedades químicas, físicas e biológicas do meio ambiente, causada por qualquer forma de matéria ou energia resultante das atividades humanas, que direta ou indiretamente, alterem a saúde, a segurança e o bem-estar da população. Neste caso, a aquicultura, além de ser praticada com o uso direto dos recursos hídricos, gera aspectos que podem ocasionar impactos negativos para a qualidade ambiental. Este capítulo tem por objetivo apresentar os possíveis impactos causados pela aquicultura ao meio ambiente, bem como demonstrar as possibilidades do desenvolvimento da atividade de forma sustentável, por meio do planejamento e da adoção de medidas de controle, mitigação ou intensificação dos impactos oriundos da aquicultura, fundamentados em práticas de manejo e conservação de base agroecológica. Medicamentos utilizados, arraçoamento, uso de hormônios, fertilização dos viveiros, foram algumas das atividades identificadas na aquicultura capazes de causar impacto ao ambiente: porém, deve-se considerar quais possuem potencialidade de produzir impactos significativos. Propostas com base nos princípios agroecológicos para estes impactos encontrados foram o uso de policultivos, consórcios de culturas, alimentação alternativa, reuso e reaproveitamento de resíduos. Mais importante que identificar os impactos, é buscar propostas com ações proativas, mitigadoras e corretivas, bem como propor alternativas para que esses impactos negativos ocorram em menor escala ou, sempre que possível, não ocorram.

Palavras-chave: Aquicultura; conservação ambiental; práticas agroecológicas.

\section{Introdução}

No cenário mundial, a pesca exerce importante papel na economia mundial e na geração de empregos (SEBRAE, 2018), bem como possui outros aspectos relevantes, tais como: alimentação de qualidade, recreação (pesca recreativa ou pesca desportiva), ornamentação (espécies ornamentais) e fins industriais (incluindo a fabricação de rações para alimentação animal). 
Além da pesca, é possível obter animais aquáticos para esses diversos fins, pela aquicultura, que é o cultivo, normalmente em espaço confinado e controlado, de organismos aquáticos, tais como: peixes, crustáceos, moluscos, algas, répteis e qualquer outra forma de vida aquática de interesse econômico produtivo (SCHULTER e VIEIRA FILHO, 2017).

A aquicultura envolve o cultivo de animais em água doce e de água salgada sob condições controladas. Atualmente, a aquicultura é responsável pela produção da metade dos peixes e moluscos consumidos pela população mundial. A produção de pescado alcançou em 2016 a marca de 171 milhões de toneladas, sendo 88\% utilizadas para o consumo humano: graças à estabilidade da produção e 0 crescimento a aquicultura contribui para o crescimento econômico e a luta contra a pobreza mundial (FAO, 2018).

No Brasil, a aquicultura tem crescido a uma média de $30 \%$ ao ano - índice superior à média mundial, que é de $10 \%$ a. a. Na região Sudeste, o crescimento acompanha 0 perfil do setor no país (SCHULTER e VIEIRA FILHO, 2017). Segundo SEBRAE (2018), a aquicultura é a atividade agropecuária que mais cresce no Brasil e no mundo; consequentemente, surgem novas oportunidades de mercado. Embora gere renda, empregos e seja importante nacionalmente e mundialmente, devem-se considerar outros fatores, relevantes em sistemas de produção modernos, tais como os fatores econômicos, sociais e ambientais.

A aquicultura é uma atividade que pode ser praticada de forma sustentável, com custo de investimento relativamente baixo e produtividade elevada, que apresenta capacidade de ampliar a produção mundial de alimentos de forma significativa, contribuindo, assim, para a maior segurança alimentar no mundo (SIQUEIRA, 2017). Porém, é importante mencionar a possibilidade de impactos e externalidades ambientais negativos significativos.

Para qualquer implantação e manutenção de uma atividade econômica, é necessária a alteração e adequação de ambientes. As diferentes modalidades da aquicultura podem gerar impactos ambientais diversos, dependendo do tipo de sistema de cultivo e das espécies utilizadas (BARBIERE et al., 2014). Sendo assim, os impactos ambientais devem ser considerados e analisados, já que a aquicultura e realizada no ambiente aquático e a água é considerada um dos recursos naturais mais importantes para a sobrevivência e para os padrões de crescimento e desenvolvimento das gerações futuras.

O impacto ambiental é definido como qualquer alteração das propriedades químicas, físicas e biológicas do meio ambiente, causada por qualquer forma de matéria ou energia resultante das atividades humanas, que direta ou indiretamente, alterem a saúde, a segurança e o bem-estar da população (PILLAY, 1992; SOUZA, 2018).

Para a ISO 14001 (International Organization for Standardization), que é uma das normas que determinam diretrizes para garantir que determinada empresa (pública ou privada) pratique a gestão ambiental, primeiro se define ASPECTO AMBIENTAL que causará um impacto. Ou seja, aspecto ambiental é considerado qualquer elemento das atividades, produtos e serviços de uma organização que pode interagir com o meio ambiente.

É importante ressaltar a definição de aspecto e impacto ambiental, onde o aspecto é originado do consumo de insumos ou da geração de resíduos, nas diversas atividades de uma organização; e o impacto ambiental é definido como qualquer modificação do meio ambiente, adversa ou benéfica, que resulte, no todo ou em partes, das 
atividades, produtos e serviços de uma organização. Sendo assim, o impacto ambiental é uma consequência do aspecto ambiental (SOUZA et al., 2014).

Ainda, descrito por Pillay (1992), as atividades sociais e econômicas, a biota, as condições estéticas e sanitárias do meio ambiente e a qualidade dos recursos ambientais que forem alteradas por determinado fator ambiental é considerado um impacto. De acordo com Tommasi (1994), essas alterações necessitam ser quantificadas porque apresentam variações positivas ou negativas, grandes ou pequenas.

Para Pillay (1992), os mais relevantes impactos provenientes da aquicultura, de forma geral, consiste em conflitos dos corpos d'água, a sedimentação e obstrução dos fluxos de água, a eutrofização, a descarga dos efluentes de viveiros e a poluição por resíduos químicos empregados nas diferentes fases do cultivo.

O objetivo do estudo dos impactos ambientais é avaliar as consequências das ações antrópicas, para a busca por medidas de controle e mitigação ou intensificações dos mesmos, por intermédio de projetos ou ações. No Brasil, a Avaliação de Impacto Ambiental (AIA) envolve um conjunto de técnicas de gestão ambiental com o objetivo de identificar e interpretar os aspectos e impactos; ou seja, a relação de causa-efeito sobre o meio ambiente decorrente de ações propostas de desenvolvimento.

Este capítulo tem por objetivo apresentar os possíveis impactos causados pela aquicultura ao meio ambiente, bem como demonstrar as possibilidades do desenvolvimento da atividade de forma sustentável, por meio do planejamento e da adoção de medidas de controle, mitigação ou intensificação dos impactos oriundos da aquicultura, fundamentados em práticas de manejo e conservação de base agroecológica.

\section{Aquicultura}

A Aquicultura é definida pela Food and Agriculture Organization (FAO, 2018), como cultivo de organismos aquáticos, tais como peixes, crustáceos, moluscos e plantas aquáticas, em água doce e em água salgada, sob condições controladas. Atualmente, a aquicultura é responsável pela produção da metade dos peixes e moluscos consumidos diretamente pela população mundial. A produção pesqueira mundial alcançou uma produção máxima de 171 milhões de toneladas em 2016, dos quais a aquicultura representou $47 \%$. O valor total da primeira venda da produção pesqueira e da aquicultura em 2016 se estimou em 362 bilhões de dólares, dos quais 232 bilhões procederam da aquicultura (FAO, 2018).

A atividade de aquicultura difere da produção nos ecossistemas naturais em três aspectos básicos (HENRY-SILVA e CAMARGO, 2006):

O primeiro aspecto está relacionado à existência de entrada de energia auxiliar, além da energia solar, como é o caso de ecossistemas naturais. Esta energia auxiliar está sob controle do homem, consistindo em trabalho humano e animal, fertilizantes, ração, água de abastecimento, medicamentos e combustível para movimentar a maquinaria;

O segundo aspecto diz respeito à pequena diversidade de organismos aquáticos, objetivando maximizar a produção de apenas algumas espécies de maior valor comercial; e 
O terceiro aspecto refere-se à seleção artificial que plantas e animais cultivados, geralmente, são submetidos: também, com o intuito de aumentar a produção e, consequentemente, o lucro obtido com a comercialização desses organismos.

Segundo a Resolução CONAMA $\mathrm{n}^{\circ}$ 001, de 23 de janeiro de 1986, existe a obrigatoriedade da realização do estudo de impacto ambiental (EIA) e da elaboração do relatório de impacto ambiental (RIMA) para as atividades modificadoras do meio ambiente: neste sentido, a aquicultura se enquadra por ser uma atividade que modifica as condições naturais do meio em que está inserida.

Os ambientes aquáticos estão constantemente susceptíveis a impactos diversos: podem ser oriundos da disposição inadequada de resíduos domésticos, agrícolas e industriais que possuem elevada carga orgânica e inorgânica, da eliminação das matas ciliares, da erosão e do assoreamento, da pesca predatória, e da introdução de espécies exóticas, bem como pela própria expansão desta atividade. Dessa forma, a aquicultura vem sendo apontada como um potencial impacto aos ecossistemas naturais (SOUZA et al., 2014; ZACARIAS e SOUZA, 2019).

A aquicultura pode ser realizada em diversificados níveis de produção, onde o efluente e os resíduos produzidos, oriundos desta atividade dependem basicamente da água de abastecimento, das espécies cultivadas, da densidade, do tempo de residência, da quantidade e da qualidade de alimentos fornecidos e da biomassa dos organismos (SHILO e RIMON, 1982; BAIRD et al., 1996; SOUZA et al., 2014).

A intensidade do impacto, a duração e significância, vão depender da produção e da forma que é conduzida - a tendência, na medida em que a produção aumenta, potencializam-se os efeitos dos impactos negativos sobre o ambiente (ZACARIAS e SOUZA, 2019).

Silvert (1992), citado por Henry-Silva e Camargo (2006), que avaliaram impactos da atividade de aquicultura, classifica os impactos da aquicultura como interno, local e regional: a) interno e local, quando ocorre dentro do lugar de produção, por exemplo, a alteração nos parâmetros físico-químicos-biológicos da agua no viveiro; e b) regional, quando os efeitos são mais abrangentes, atingindo pontos distantes do lugar da atividade, incluindo até pontos externos à microbacia hidrográfica onde se localiza a atividade.

\section{Diagnóstico ambiental: cenário atual, pré e pós-degradação}

Baccarin (2002), avaliando o impacto ambiental da produção de tilápia do Nilo sob diferentes manejos alimentares, demonstrou que o aumento da biomassa dos peixes, ocasionou redução gradativa dos teores de oxigênio dissolvido e o aumento dos valores de turbidez e de sólidos em suspensão do efluente. Henry-Silva (2001) associou este fato ao aumento do arraçoamento, ao aumento dos dejetos e à decomposição da matéria orgânica.

Persson (1991), ao analisar o impacto da implantação de tanques-redes com truta arco-íris em um lago da Suécia, verificou que os efluentes e os resíduos originários desta atividade ocasionaram aumento da produção fitoplâncton, devido à elevada quantidade de fosfato na coluna d'água.

Menezes e Beyruth (2003), analisando os impactos de tanques-rede com tilápia do Nilo sobre a comunidade bentônica da represa de Guarapiranga (SP), observaram maiores porcentagens de Oligochaetas no sedimento abaixo dos tanques-rede, 
provavelmente em decorrência do aumento dos teores de matéria orgânica e de nutrientes provenientes das excretas dos peixes.

Os efeitos, porém, como descrito por Silvert (1992), não atingem apenas o local onde acontece a atividade. Boaventura et al. (1997) observaram que os efeitos dos efluentes de fazendas de criação de truta arco íris (O. mykiss) foram identificados a 12 $\mathrm{km}$ de distância a jusante do ponto de seu lançamento, acarretando no aumento da população bacteriana. Macedo (2004) constatou maiores densidades de coliformes fecais em um ambiente aquático que recebia fluxo intenso de efluentes de aquicultura, sugerindo a necessidade do tratamento desses efluentes antes do lançamento no corpo d'água receptor.

Na realização do Diagnóstico Ambiental visando a elaboração dos Cenários atual e, ou, pré-degradação, foram destacados os principais os aspectos associados às práticas diárias da aquicultura capazes de produzirem os principais impactos ambientais das atividades de aquicultura (MIRES, 1995; BARDACH, 1997; MIDLEN; REDDING, 1998; SOUZA, 2015; HENRY-SILVA; CAMARGO, 2008; SOUZA, 2018):

- Introdução de espécies exóticas ao ambiente de criação;

- Aumento das concentrações de nitrogênio e fósforo na coluna d'água;

- Acúmulo de matéria orgânica no sedimento;

- Fluxo constante da água e a geração de outros resíduos.

Outros impactos identificados por Barbieri et al. (2014) foram:

- Perda da qualidade da água (relacionado aos fatores citados acima);

- Modificação do habitat;

- Impacto visual e até o social, em casos específicos.

No presente trabalho, serão destacados:

\subsection{Medicamentos utilizados na aquicultura}

Os antibióticos e antimicrobianos são substâncias que podem ser extraídas de plantas, produzidas por microrganismos ou em laboratórios de maneira artificial, que como característica comum apresentam a capacidade de matar ou inibir o crescimento de bactérias (FIGUEIREDO, 2016). Segundo dados da FAO (2018), os antibióticos mais utilizados na aquicultura mundial, em nível mundial, são a oxitetraciclina, o florfenicol, a sarafloxacina, a eritromicina e as sulfonamidas.

No ecossistema aquático o uso dessas substâncias ocasiona grande impacto no ambiente, atrelado à permanência de resíduos químicos na água, bem como a seleção de bactérias e outros agentes resistentes. Leira et al. (2017) alertaram quando a existência de uma barreira ao comércio internacional, onde, nos últimos anos, tem-se preocupado com a incidência desses resíduos de antibióticos em carcaças de peixes.

Figueiredo (2016) também descreve os riscos quanto ao uso desses medicamentos, podendo causar impacto direto a produção, caso sejam utilizados de forma inadequada, que podem acumular no organismo dos animais, podendo contaminar os seres humanos. Além disso, o uso dessas substâncias pode ser altamente nocivo para o meio ambiente. Principalmente em pisciculturas realizadas em tanques-rede, onde esses estão localizados em grandes bolsões de água como represas, lagos e rios, onde esses resíduos podem alterar a composição microbiana do local. 
Quando essas substâncias são eliminadas no corpo d'água, essas moléculas podem se depositar no sedimento ou for ingerida por outros animais ali presentes, alterando 0 perfil de microrganismos e induzindo a seleção daqueles que são resistentes a essas moléculas (FIGUEIREDO, 2016). Sapkota et al. (2008) mencionaram a resistência de alguns genes de bactérias que podem não ser patogênicas em organismos aquáticos; porém, patogênicos aos seres humanos.

Balcázar et al. (2006) citam que, nas instalações para produção em grande escala, os peixes podem ser expostos a condições estressantes, que levam aos problemas relacionados às doenças e à degradação das condições ambientais: isso ocasiona normalmente a um aumento na utilização de medicamentos de uso veterinário. Levings (1994) já alertava para o fato de aumento da produção de peixes e, consequentemente, um substancial aumento no uso de substâncias químicas para controlar pragas e parasitas.

Beveridge (1996) apontou em seu trabalho a utilização de vários agentes químicos nas mais distintas modalidades de aquicultura. Como exemplo, citou os elementos utilizados na construção, proteção contra corrosão, além de serem encontrados pigmentos e desinfetantes, mesmo que em quantidades pequenas.

Segundo Teles e Reyes (2014), os dados sobre os impactos causados no ambiente devido ao uso exacerbado de medicamentos são escassos; outro entrave é que não existe regulamentação e fiscalização para o uso dessas drogas nos ambientes aquáticos (CARNEIRO et al., 2007).

Neste sentido, quando a utilização inadequada e descontrolada de medicamentos levanta a hipótese de impactos não apenas sobre a resistência de microrganismos, mas também na quantidade de resíduos liberados nos alimentos, reforçando a importância do desenvolvimento de trabalhos relacionados aos impactos do uso de medicamentos na aquicultura.

\subsection{Uso de hormônios}

Com a crescente atividade de aquicultura por pequenos produtores, que produzem seus próprios alevinos e larvas, a utilização de hormônios para propagar artificialmente os peixes tem avançado de forma significativa. A reprodução é a fase mais importante na vida do animal, pois é ela que garantirá a perpetuação da espécie. É um processo fisiológico complexo, onde atuam diversos eventos neuro-hormonais que, por intermédio de estímulos ambientais, ocasionam no peixe reações específicas que culminam com a desova (VENTURIERI; BERNARDINO, 1999).

Várias substâncias podem ser utilizadas com a finalidade da reprodução artificial em piscicultura: os mais utilizados são os hormônios liberadores de gonadotropinas, os antagonistas de dopamina e os hormônios hipofisários (VENTURIERI; BERNARDINO, 1999).

Ainda, segundo esses mesmos autores, a manipulação dos hormônios ou análogos, deve ser feita com cuidado uma vez que são drogas potentes e sua ação em humanos é similar à esperada em peixes - estimulação de gonadotropinas e liberação de hormônios sexuais - com a importante diferença que a administração crônica em humanos conduz a um decréscimo na liberação de gonadotropinas e, portanto, de esteroides sexuais.

Entre os hormônios utilizados para a inversão sexual, está o 17-a-metiltestosterona pelo período de 21 a 28 dias, que pode ser realizada na adição do hormônio na ração 
dos peixes ou no banho de imersão, sendo a primeira mais viável ambientalmente. Entretanto segundo Dias-Koberstein (2007), uma hipótese de inconveniente da aplicação deste hormônio é a água residual, que é lançada nos corpos receptores, contaminando-os, levando a um desequilíbrio ambiental com a masculinização dos peixes da região, podendo ocasionar a extinção da espécie (DIAS-KOBERSTEIN, 2007).

Porém, vale ressaltar que esse hormônio fará efeito apenas nos primeiros dias de vida dos organismos, no início da embriogênese, onde o indivíduo não é fenotipicamente macho ou fêmea, pois não possui características associadas ao sistema reprodutor, possuindo apenas as células germinativas primordiais que determinará o sexo (DRUMMOND, 2007). Portanto, não afetarão todos os organismos dentro de um corpo hídrico, apenas aqueles em fase inicial da vida, sendo o impacto ambiental referente a este aspecto, considerado baixo.

Outro ponto a se considerar, é o fato do hormônio ser fotossensível e termossensível: em temperaturas acima de $30^{\circ} \mathrm{C}$ ele perde sua estabilidade (MCEVOY, 2007). Este fato pode ser uma informação importante quando se fala em contaminação dos corpos hídricos, mostrando que nem sempre o hormônio terá o potencial de inversão sexual nos organismos. Além disso, nem todas as espécies são invertidas - isso pode ser uma justificativa aos trabalhos que mostram os impactos significativos deste produto quando lançados nos corpos hídricos.

Drummond (2007) cita em seu trabalho que um dos principais argumentos utilizados para defender o uso de hormônios em peixes de linhagens monossexos: é que a quantidade de anabolizante ingerida por animal é muito pequena, inferior a $5 \mathrm{mg}$ por animal. Autores como Abucay e Mair (1997) e Curtis et al. (1991) demonstraram que a maior parte do hormônio ingerido é eliminado rapidamente, não se acumulando na carne que será consumida pelos seres humanos.

Outro argumento a favor, é que se utilizado de forma correta, seguindo os protocolos indicados na literatura, esse hormônio é detectado aos níveis de parte por milhão nos peixes revertidos em tamanho comercial, o que não ofereceria problemas a saúde humana (DRUMMOND, 2007), e possivelmente suas concentrações são provenientes da própria produção do indivíduo.

Estudo realizado por Contreras-Sánchez e Couturier (2002) não detectou a presença do hormônio de inversão na água durante seus experimentos em sistemas fechados, apenas no solo, 17 dias após o início do experimento, que mais tarde foi decomposto pela ação microbiológica. Em sistemas abertos, de água corrente, os metabólitos são perdidos (DRUMMOND, 2007).

\subsection{Arraçoamento}

O manejo alimentar quando feito de forma equivocada, pode reduzir a absorção de nutrientes pelos peixes, o que potencializa a produção de matéria orgânica e disponibilidade nutrientes nos sistemas de produção, podendo levar a alteração na qualidade da água e causar o aumento do fitoplâncton, redução da transparência da água e diminuição do oxigênio dissolvido, além de poder ocasionar impactos ambientais significativos, como a contaminação do recurso hídrico, comprometendo assim a saúde dos peixes (CYRINO et al., 2010).

O aumento na concentração de nutrientes na água, em especial fósforo e nitrogênio, potencializa o crescimento exacerbado de biomassa, podendo caracterizar uma eutrofização e trazer alterações para a demanda biológica por oxigênio, alterações no 
$\mathrm{pH}$, turbidez e liberação de toxinas, podendo ocasionar mortandade de peixes e outros organismos (SOUZA et al., 2014; AVELLAR; NEDER; COTTA, 2015; SOUZA, 2015).

Boyd (2003) e Baccarin e Camargo (2005), demonstraram que parte da ração fornecida é incorporada na biomassa dos peixes e parte continua na água. As rações adicionadas à dieta dos organismos aquáticos contribuem com a adição de nitrogênio nos efluentes das atividades de aquicultura, sendo parte desse elemento excretado pelos organismos na forma de amônia e o restante eliminado pelas fezes na forma de nitrogênio orgânico. Os fertilizantes orgânicos, compostos vegetais e esterco animal, são ricos em fósforo (GOMES, 2016).

Kubitza (1998) cita que valores de amônia não ionizada acima de 0,20 $\mathrm{mg} \mathrm{I}^{-1}$ já são suficientes para comprometer o crescimento, levando a uma toxidez crônica e potencializando a diminuição da tolerância dos peixes às doenças.

Pereira (2008) e Mercante; Silva; Costa (2006) encontraram valores de concentração de nitrogênio e fósforo distintos em efluentes da piscicultura, mas evidenciaram a possibilidade de eutrofização devido a concentração dessas substâncias.

Estudos relatam que somente 25 a $30 \%$ do nitrogênio e fósforo fornecidos no arraçoamento e fertilizantes serão aproveitados para a formação da biomassa de peixes e camarões, sendo que o restante do nitrogênio e fósforo fica retido no sedimento dos viveiros ou é eliminado pelo efluente (CASILLAS-HERNÁNDEZ et al., 2006; SILVA et al., 2013). Mercante et al. (2004) encontraram valores superiores a $0,025 \mathrm{mg} / \mathrm{L}$ de fósforo total, caracterizando locais ricos em nutrientes e com qualidade da água não adequada.

Macedo e Sipaúba-Tavares (2010) descrevem que os nutrientes, nitrogênio e fósforo podem ser limitantes no ecossistema aquático, podendo acelerar o processo de eutrofização quando introduzidos no ambiente e, consequentemente, estimulam a produtividade de plantas aquáticas podendo comprometer a produção de interesse.

Vaz et al. (2015) realizaram estudo de caso analisando a qualidade da água de efluente de piscicultura no estado do Paraná, de acordo com a Resolução CONAMA $n^{\circ} 357 / 04$, e concluíram que o efluente da piscicultura avaliada estava dentro do padrão permitido para o lançamento dos corpos receptores.

Embora existam trabalhos que demonstrem os impactos advindos do arraçoamento na aquicultura, é importante considerar a modalidade da atividade e realizar análises que comprovem o impacto ambiental.

\subsection{Introdução de espécies exóticas}

Oliveira et al. (2014) apontam que os impactos da introdução de espécies exóticas podem ser tanto ambiental como socioeconômico. A introdução de espécies exóticas pode afetar os ecossistemas aquáticos por meio da predação, competição, alterações genéticas, alteração de habitats e introdução de patógenos (DIAS - Database on Introductions of Aquatic Species, FAO, 2000).

Mudanças no ambiente onde são introduzidas as espécies estranhas são recorrentes, pois cria a competição com os animais nativos e altera o fluxo de energia dentro da cadeia alimentar (CUNHA et al., 2011; SOUZA et al., 2014). A invasão dessas espécies pode ocorre de várias formas, como descreve Cunha et al. (2011):

- Escapes acidentais pela água de efluente dos tanques e viveiros; 
- $\quad$ Acidentes por rompimento;

- Transbordo de tanques;

- Soltura de indivíduos remanescentes durante o esvaziamento; e

- Descartes resultantes das atividades de manejo dos tanques.

Conhecendo a possibilidade de impacto, é necessário que se faça o estudo do impacto causado pela espécie invasora, mas principalmente tomar as medidas preventivas para que o impacto não ocorra.

\section{Cenário pós-degradação (Prognóstico): Práticas Agroecológicas para a Aquicultura}

A Ecologia estuda o funcionamento dos ecossistemas. Refere-se ao sistema natural de cada local envolvendo seus fatores bióticos, como os seres vivos, e os abióticos, como solo e o clima e com a inter-relação entre esses fatores, que caracteriza cada ambiente. O manejo ecológico dos agroecossistemas é realizado conforme as características locais do ambiente, alterando-as o mínimo possível onde o potencial endógeno deve ser aproveitado. A agroecologia depende muito da sabedoria de cada agricultor, desenvolvida a partir de suas experiências e observações locais (PRIMAVESI, 2008; GONÇALVES et al., 2019).

Além disso, cada produtor, principalmente pertencente à agricultura familiar, ponto chave da agroecologia, possui suas dificuldades e necessidades e assim pode, utilizando princípios de agroecologia para melhorar a produção, diminuir gastos com insumos externos, além de potencializar a obtenção de renda extra: devido à diversidade dos produtos obtidos (ZACARIAS; SOUZA, 2019).

Diversas são as possibilidades de incluir na aquicultura alternativa mais sustentável, utilizando conceitos e princípios da agroecologia: como resultado, alcançam-se benefícios diversos para a qualidade de vida e o ambiente.

Primavesi (2008) e Gonçalves et al. (2019), apontam que a biodiversidade é um dos fatores mais importantes dentro da agroecologia, pois a manutenção de grande diversidade de organismos em uma mesma área é uma estratégia da natureza para construir maiores níveis de estabilidade na produção biológica. Neste caso, a aquicultura, por ser realizado dentro do recurso natural (água) e ao promover a diversidade de espécies, poderá proporcionar maior equilíbrio ao ecossistema, maiores fontes de alimento e redução de pragas e doenças comuns nos monocultivos.

A conservação da água, bem como sua reutilização, é outro ponto importante que perpassa por conceitos agroecológicos: também podem ser utilizadas na aquicultura, alternativas que buscam melhorar a qualidade da água que sofre alteração durante todo o processo produtivo de animais aquáticos.

Neste sentido, estratégias que minimizem os impactos ambientais negativos no recurso hídrico, que busquem equilibrar e manter os parâmetros de qualidade da água é sempre bem vista em rotinas agroecológicas. No Ifes campus de Alegre, por exemplo, antes de ser lançado no corpo hídrico, o efluente dos viveiros vai para a lagoa de decantação, onde existem organismos filtradores e plantas que auxiliam no processo de diminuição da carga orgânica (Figura 1). 


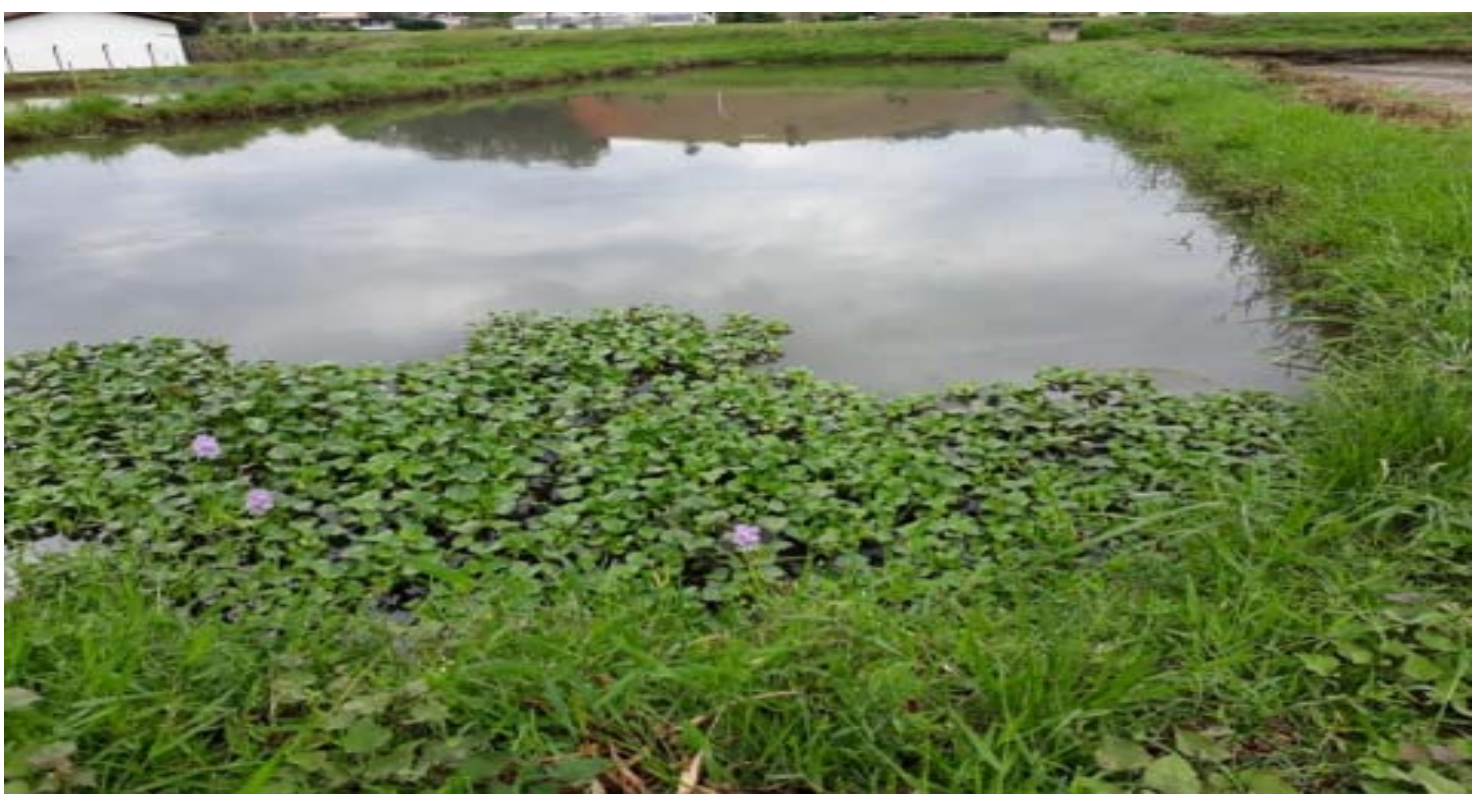

Figura 1. Plantas aquáticas que atuam na diminuição da carga orgânica do efluente gerado pelo setor de aquicultura do IFES - Campus de Alegre.

Tratando-se da alimentação dos animais aquáticos, muitas vezes é feita com rações comerciais que deixa resíduos normalmente depositados no fundo dos tanques ou viveiros, ou que seguem pelo efluente atingindo o corpo receptor. Em contraponto a esta questão, a agroecologia também aponta para a necessidade da diminuição dos recursos exógenos e da independência e soberania do produtor: pode utilizar outras fontes de alimentos, principalmente os oriundas do próprio local onde está inserido, diminuindo custos de produção, a entrada de energia exógena e substâncias presentes na ração que não naturais do local, por exemplo. Na Tabela 1 são relacionadas propostas de práticas agroecológicas que poderão ser utilizadas na atividade de aquicultura, com o objetivo de se reduzir os impactos ambientais e as externalidades.

Tabela 1. Propostas de práticas agroecológicas para a Aquicultura.

\begin{tabular}{lll}
\hline Prática & Alternativa & Benefícios \\
Aquicultura & Agroecológica & \\
\hline
\end{tabular}

Qualidade da água

Reaproveitamento do recurso
A água pode ser reutilizada por meio de Sistemas de Recirculação de Água (SRAP), que possibilitam o aumento da produção com aproveitamento da água.

\section{Enriquecimento dos viveiros \\ Reuso e \\ Tratamento dos \\ Resíduos}

O enriquecimento dos viveiros pode ser feito utilizando resíduos advindos da agricultura familiar, onde o produtor não terá gastos com insumos externos, e contribuirá com o tratamento destes resíduos que poderiam causar outros tipos de poluição, caso fossem descartados de forma incorreta. 
Criação dos
animais

Diversidade de

culturas -

Policultivos e

Consórcios

Alimentação

Arraçoamento
As possibilidades para o pequeno e médio produtor são significativas neste sistema de produção, pois permite uma variedade de espécies produzidas e economia com alimentação, podendo realizar a despesca em diferentes épocas do ano, obtendo renda durante todo o período.

A possibilidade de obtenção de renda extra está relacionada à otimização da produção - a agroecologia pode potencializar a sustentabilidade da agricultura familiar, pois prioriza o uso de insumos locais, diminuindo gastos e custos para os produtores. O uso alternativo de alimentos para os animais pode trazer grandes benefícios aos produtores mediante as dificuldades encontradas.

\section{Considerações finais}

Conhecer e identificar os aspectos e impactos ambientais é uma metodologia muito utilizada para avaliar a sustentabilidade dos sistemas, os riscos e problemas causados ao meio ambiente, mostrando se são ou não significativos. Porém, mais importante que identificá-los, é buscar propostas com ações proativas, mitigadoras e corretivas, bem como propor alternativas para que esses impactos negativos ocorram em menor escala ou, sempre que possível, não ocorram.

Este trabalho buscou apresentar os aspectos e os possíveis impactos ambientais negativos oriundos da atividade de Aquicultura, podendo assim, permitir a busca por alternativas menos danosas ao ambiente. As alternativas que buscam a sustentabilidade são diversas, cabendo destacar aquelas que contribuem para 0 desenvolvimento da agricultura familiar agroecológica.

Deverão possibilitar:

- Geração de renda e emprego no campo;

- Diminuição da dependência de insumos externos, muitas vezes com altos custos, como no caso da compra de rações;

- Garantir a biodiversidade, por intermédio de consórcios e policultivos;

- Potencializar a soberania alimentar e a qualidade nutricional dos alimentos; e

- Contribuir com a disseminação do pensamento agroecológico, onde o conhecimento científico atrelado à sabedoria tradicional pode contribuir com a sustentabilidade dos agroecossistemas garantindo as futuras gerações um meio ambiente equilibrado.

\section{Referências}

ABNT NBR ISO 14001. Sistemas da gestão ambiental requisitos com orientações para uso. 2008. 27p. 
ABUCAY, J. S.; MAIR, G. C. Hormonal sex reversal of tilapias: implications of hormone treatment application in closed water systems. Aquaculture Research, v. 28, n. 11, p. 841-845, 1997. https://doi.org/10.1046/j.1365-2109.1997.00878.x.

AVELLAR, I. G.J; NEDER, A. V. F.; COTTA, T. A. P. G. Aplicação de eletrocoagulação na remoção de fosfatos em efluente doméstico artificial preparado a partir de bebida refrigerante-um experimento para graduação. Revista Virtual de Química, v. 7, n. 6, p. 2255-2272, 2015. Disponível em: <http://rvqsub.sbq.org.br/index.php/rvq/article/view/1073>. Acesso em: 05 jan. 2021.

BACCARIN, A. E.; CAMARGO, A. F. M. Characterization and evaluation of the feed management on the effluents on Nilo tilapia culture. Brazilian Archives of Biology and Technology, v. 48, n. 1, p. 81-90, 2005. https://doi.org/10.1590/S151689132005000100012.

BACCARIN, A. E. Impacto ambiental e parâmetros zootécnicos da produção de tilápia do Nilo (Oreochromis niloticus) sob diferentes manejos alimentares. Jaboticabal. 56p. Tese Doutorado. Universidade Estadual Paulista, Jaboticabal. 2002.

BALCÁZAR, J. L. et al. The role of probiotics in aquaculture. Veterinary Microbiology, v.114, p.173-186, 2006. https://doi.org/10.1016/j.vetmic.2006.01.009.

BAIRD, D. J.; BEVERIDGE, M. C. M.; KELLY, L. A.; MUIS, J. F. Aquaculture and waters recourse management. London: Blackwell Science Ltda. 219 p. 1996.

BARBIERI, E. et al. Avaliação dos Impactos ambientais e socioeconômicos da aquicultura na região estuarina-lagunar de Cananéia, São Paulo, Brasil. Revista de Gestão Costeira Integrada, v. 14, n. 3, p. 385-398, 2014. http://dx.doi.org/10.5894/rgci486.

BARDACH, J. E. Sustainable Aquaculture. New York: John Wiley \& Sons, Inc. 251p. 1997.

BEVERIDGE, M. Cage aquaculture. 2a ed. Oxford: Fishing News Books.1996. 346p.

BOYD, C. E. Guidelines for aquaculture effluent management at the farmlevel. Aquaculture, v. 226, n. 1-4, p. 101-112, 2003. https://doi.org/10.1016/S00448486(03)00471-X.

BRASIL. Resolução CONAMA 357 de 17 de março de 2005. Brasília, DF, 2005.

CARNEIRO, D. O. et al. Perfil de susceptibilidade a antimicrobianos de bactérias isoladas em diferentes sistemas de cultivo de tilápia-do-nilo (Oreochromis niloticus). Arquivo Brasileiro de Medicina Veterinária e Zootecnia, v. 59, n. 4, p. 869-876, 2007. http://dx.doi.org/10.1590/S0102-09352007000400008.

CONTRERAS-SÁNCHEZ, W. M.; COUTURIER. Fate of Methyltestosterone in the Pond Environment: use of $\mathrm{mt}$ in earthen ponds with no record of hormone usage. In: K. McElwee, K. Lewis, M. Nidiffer, and P. Buitrago (Editors), Nineteenth Annual Technical Report. Pond Dynamics/Aquaculture CRSP, Oregon State University, Corvallis, Oregon, $2002 . \quad$ Disponível em: $<$ https://www.semanticscholar.org/paper/FATE-OF-METHYLTESTOSTERONE-INTHE-POND-ENVIRONMENT\%3A-Contreras-S\%C3\%A1nchezCouturier/312e62b5bc00e9608a49bf69c4650a08e8b71735>. Acesso em: 05 jan. 2021. 
CONSELHO NACIONAL DE MEIO AMBIENTE. Resolução CONAMA $\mathbf{n}^{\circ} \mathbf{0 0 1}$, de 23 de janeiro de 1986. Disponível em: <http://www.siam.mg.gov.br/sla/ download.pdf?idNorma=8902>. Acesso em: 22 nov. 2018.

CYRINO, J. E. P. et al. A piscicultura e o ambiente: o uso de alimentos ambientalmente corretos em piscicultura. Revista Brasileira de Zootecnia, Viçosa, v. 39, supl., p. 68-87, 2010. https://doi.org/10.1590/S1516-35982010001300009.

DIAS-KOBERSTEIN, T. C. R. et al. Reversão sexual de larvas de tilápia do Nilo (Oreochromis niloticus) por meio de banhos de imersão em diferentes dosagens hormonais. Revista Acadêmica de Ciência Animal, v. 5, n. 4, p. 391-395, 2007. https://doi.org/10.7213/cienciaanimal.v5i4.10196.

FAO - Food and Agriculture Organization. The State of World Fisheries and Aquaculture. Meeting the sustainable development goals. Food and Agriculture Organization of the United Nations (FAO), Rome (Italy). 2018, 209 p. Disponível em: < http://www.fao.org/3/l9540EN/i9540en.pdf>. Acesso em: 05 jan. 2021.

FIGUEIREDO. H. C. P. Sanidade Aquícola: Antibióticos na Aquicultura. 2016. Disponível em: <https://panoramadaaquicultura.com.br/sanidade-aquicola-antibioticosna-aquicultura/>. Acesso em: 06 maio 2019.

GOMES, L. de M. Tratamento de efluente da piscicultura utilizando os processos fenton e eletroquímico: eficiência e toxicidade. Tese Doutorado. Universidade Federal de Alagoas. 2016.

GONÇALVES, D. C. et al. A agroecologia como ferramenta ao fortalecimento da agricultura familiar. Revista da UNIVAP. v.1, p.342 - 357, 2019. Disponível em: $<$ https://biblioteca.incaper.es.gov.br/digital/handle/123456789/3929>. Acesso em: 06 jan. 2021.

HENRY-SILVA, G. G.; CAMARGO, A. F. M. Impacto das atividades de aquicultura e sistemas de tratamento de efluentes com macrófitas aquáticas-relato de caso. Pesca Institute Buletim, v. 34, n. 1, p. 163-173, 2008. Disponível em: <https://repositorio.unesp.br/handle/11449/20514>. Acesso em: 06 jan. 2021.

HENRY-SILVA, G. G. Utilização de macrófitas aquáticas flutuantes (Eichhornia crassipes, Pistia stratiotes e Salvinia molesta) no tratamento de efluentes de piscicultura e possibilidades de aproveitamento da biomassa vegetal. Jaboticabal. 79p. 2001.

HENRY-SILVA, G. G.; CAMARGO, A. F. M. Composição química de macrófitas aquáticas flutuantes utilizadas no tratamento de efluentes de aquicultura. Sociedade Brasileira da Ciência das Plantas Daninhas, Viçosa-MG, v. 24, n.1, p. 21-28, 2006. https://doi.org/10.1590/S0100-83582006000100003.

KUBITZA, F. Qualidade da água na produção de peixes - Parte III (final). Panorama Aquicult, $\quad$ v. $8, \quad$ p. 35-43, $1998 . \quad$ Disponível em: $<$ https://panoramadaaquicultura.com.br/qualidade-da-agua-na-producao-de-peixesparte-iii-final/>. Acesso em: 06 jan. 2021.

LEIRA, M. H. et al. Problemas sanitários das pisciculturas brasileiras. PUBVET, v.11,
$\mathrm{n}$.
6 ,
p. 538-544,
2017.
Disponíve
em: 
<https://www.pubvet.com.br/artigo/3933/problemas-sanitaacuterios-das-pisciculturasbrasileiras>. Acesso em: 06 jan. 2021.

LEVINGS, C. D. Some ecological for net-pen culture of salmon on the coasts of the Northeast Pacific and Atlantic Oceans, with special reference to British Columbia. Journal Applied Aquaculture, v.4, n.1, p.65-141, 1994. https://doi.org/10.1300/J028v04n01_06.

MACEDO, C.F. Qualidade da água em viveiros de criação de peixes com sistema de fluxo contínuo. Jaboticabal. 136p. Tese de Doutorado. Universidade Estadual Paulista. 2004.

MACEDO, C. F.; SIPAÚBA-TAVARES, L. H. Eutrofização e qualidade da água na piscicultura: consequências e recomendações. Pesca Institute Buletim, v. 36, n. 2, p. 149-163, 2010. Disponível em: <https://www.pesca.sp.gov.br/36_2_149-163rev.pdf>. Acesso em: 06 jan. 2021.

MCEVOY, G. K. AHFS Drug Information. American Society of Health-System Pharmacists, Bethesda, MD, v. 2184, 2007.

MERCANTE, C.T.J. et al. Water quality in fee-fishing ponds located in the São Paulo metropolitan region, Brazil: analysis of the eutrophication process. Acta Limnologica Brasiliensia, Botucatu, 16(1): 95-102. 2004.

MERCANTE, C.T.J.; SILVA, D.; COSTA, S.V. 2006 Avaliação da qualidade da água de pesqueiros da região metropolitana de São Paulo por meio do uso de variáveis abióticas e da clorofila a. In: ESTEVES, E.K. e SANT'ANNA, C.L. Pesqueiros sob uma visão integrada de meio ambiente, saúde pública e manejo: um estudo na região metropolitana. São Carlos: Rima. p.37-48.

MIDLEN, A.; REDDING, T. Environmental Management for Aquaculture. Netherlands: Kluwer Academic Publishers. 1998.

MIRES, D. Aquaculture and the aquatic environment: mutual impact and preventive management. The Israeli Journal of Aquaculture - Bamidgeh, .v. 47, p. 163-172, 1995.

OLIVEIRA, C. R. et al. Composição físico-química e valores energéticos de farinhas de silagem de peixe para frangos de corte. Arq. bras. med. vet. Zootec., v. 66, n. 3, p. 933-939, 2014. https://doi.org/10.1590/1678-41626127.

PEREIRA, J. S. Avaliação do impacto do efluente de piscicultura sobre o corpo receptor. São Paulo, 2008.

PILLAY, T. V. R. Aquaculture and the environment. Fishing News Books, Blakwell Scientific Publications Ltda., New York, USA. 1992. 189p.

PRIMAVESI, A. M. Agroecologia e manejo do solo. Revista Agriculturas, v. 5, n. 3, p. 7-10, $2008 . \quad$ Disponível em: $<$ https://anamariaprimavesi.com.br/2019/06/14/agroecologia-e-manejo-do-solo-revistaagriculturas-experiencias-em-agroecologia-leisa-brasil-set-2008-vol-5-no-3/>. Acesso em: 06 jan. 2021.

SAPKOTA, A. et al. Aquaculture practices and potential human health risks: current knowledge and future priorities. Environment Institut, v. 34 p. 1215-1226, 2008. https://doi.org/10.1016/j.envint.2008.04.009. 
SCHULTER, E. P.; VIEIRA FILHO, J. E. R. Evolução da Piscicultura no Brasil: diagnóstico e desenvolvimento da cadeia produtiva de tilápia. Texto para Discussão. Instituto de Pesquisa Econômica Aplicada - ipea, 2017. Disponível em: $<$ http://repositorio.ipea.gov.br/bitstream/11058/8043/1/td_2328.pdf $>$. Acesso em: 06 jan. 2021.

SEBRAE NACIONAL. Saiba como funciona comércio de peixes no Brasil. Canal de Distribuição. 2018. Disponível em: < https://www.sebrae.com.br/sites/PortalSebrae/ artigos/artigosOrganizacao/saiba-como-funciona-comercio-de-peixes-no-brasil,8bc2 38e243312510VgnVCM1000004c00210aRCRD>. Acesso em: 28 abr. 2019.

SHILO, M.; RIMON, A. Factors which effect the intensification of fish breeding in Israel. 2. Ammonia transformation in intensive fish ponds. Bamidgeh, v. 34, n. 3, p. 101114, 1982.

SIQUEIRA, T. V. de. Aquicultura: a nova fronteira para aumentar a produção mundial de alimentos de forma sustentável. 2017. Disponível em: <http://repositorio.ipea.gov.br/handle/11058/8142>. Acesso em: 06 jan. 2021.

SOUZA, M. N. et al. Dynamic o systems and the modeling with the use STELLA. Academic Journals Database, v.4, p.23-37, 2014.

TELES, J. A.; REYES, F. G. R. Antimicrobianos na piscicultura: uso e aspectos regulatórios no Brasil. In: MADI, R. R. et al. Patologia e sanidade em ambientes aquáticos. Maringá: Massoni, p. 245-268. 2014.

TOMMASI, L. R. Estudo de Impacto ambiental. CETESB, Terragraph Artes e Informática, São Paulo, SP, Brasil. 1994. 355 p.

VENTURIERI, R.; BERNARDINO, G. Hormônios na reprodução artificial de peixes. Panorama da Aquicultura, v. 9, n. 55, p. 39-48, 1999. Disponível em: $<$ https://panoramadaaquicultura.com.br/hormonios-na-reproducao-artificial-depeixes/\#: : :text=O\%20uso\%20de\%20antiestr\%C3\%B3genos\%2C\%20progestinas, dele s\%20ser\%C3\%A1\%20visto\%20a\%20seguir>. Acesso em: 06 jan. 2021.

ZACARIAS, A. J.; SOUZA, M. N. Recuperação de área degradada de monocultura intensiva no estado do Espírito Santo. Revista Univap, v.1, n. 87, p.234-242, 2019.

\section{Autores}

Ronald Assis Fonseca, Mauricio Novaes Souza*, Pedro Pierro Mendonça, Hilton Moura Neto, Credigar Gonçalves Moreira, José Carlos V. da Paschoa, Lucinea Carolina Horsth, Aline Marchiori Crespo, Geisa Corrêa Louback

Programa de Pós-Graduação em Agroecologia, Instituto Federal do Espírito Santo Campus de Alegre. Caixa Postal 47, CEP: 29500- 000, Alegre-ES.

*Autor para correspondência: mauricios.novaes@ifes.edu.br 